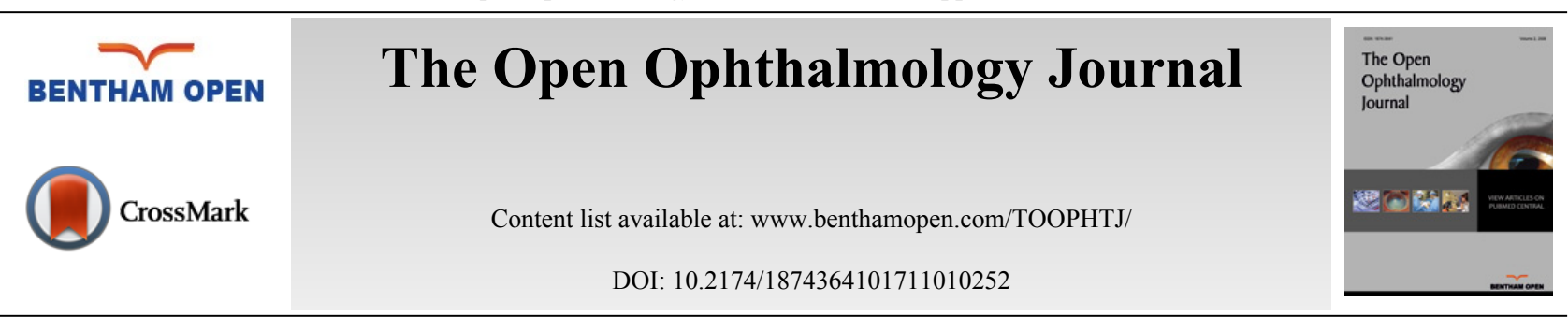

REVIEW ARTICLE

\title{
Pathophysiology of Keratoconus: What Do We Know Today
}

\author{
Uri Soiberman, James W. Foster, Albert S. Jun and Shukti Chakravarti* \\ Cornea Division, Wilmer Eye Institute, Johns Hopkins University School of Medicine, Baltimore, USA
}

Received: February 18, 2017

Revised: April 01, 2017

Accepted: June 14, 2017

\begin{abstract}
Keratoconus is a common corneal ectasia that leads to progressive visual impairment. Numerous studies have shown abnormal protein expression patterns in keratoconic corneas. However, the specific mechanisms causing this disease remain ambiguous. This review aims to provide an update on morphological studies of the keratoconic cornea, relate these early studies with current findings from proteomic, biochemical and cell culture studies and to postulate possible pathogenic pathways.
\end{abstract}

Keywords: Keratoconus, Pathogenesis, Morphology, Proteomics, Cytokine, Oxidative stress, TGF- $\beta$, Keratocytes, Corneal epithelium.

\section{INTRODUCTION}

Keratoconus $(\mathrm{KC})$ is a common ectasia of the cornea $[1,2]$. Its reported incidence ranges between $50-230$ per 100,000 and the estimated prevalence is 54.5:100,000. Clinically, the central or paracentral corneal stroma undergoes progressive thinning and loss of structural integrity that leads to bulging of the cornea, which gives the cornea its typical cone shape appearance in KC. The disease process in the cornea results in a myopic shift and irregular astigmatism that may cause significant impairment in visual function and may not be amenable to spectacle correction. Disease onset is usually at youth or adolescence with a gradual progression over the first few decades. $\mathrm{KC}$ may be an isolated finding or it may be associated with other systemic disorders or syndromes, such as: Down syndrome, Leber congenital amaurosis and connective tissue diseases (for instance: Ehlers Danlos, Marfan syndrome, etc.). Another association that has been made was atopy, and at least one study has shown elevated serum IgE levels in $\mathrm{KC}$ patients when compared to non $\mathrm{KC}$ patients [3]. The central corneal thickness (CCT), with respect to congenital and familial cases, may be a genetic trait as shown by a recent genome-wide association analyses that identified multiple loci which confer susceptibility to low CCT and keratoconus. [4]Specifically, two small nuclear polymorphisms were identified to confer high risk for developing KC: FOXOland FNDC3B. FOXO1 acts by regulating the TGF- $\beta$ pathway, which by itself may be implicated in the pathogenesis of $\mathrm{KC}[5]$.

Additionally, evidence for the role of genetics in $\mathrm{KC}$ comes from prior evidence of familial aggregation of $\mathrm{KC}$ : unaffected relatives of $\mathrm{KC}$ patients may have abnormal videokeratography indices [6]. This finding is of consequence as these apparently unaffected relatives may have a similar shape to their corneas and thus may be undergoing a silent subclinical disease process. Additional evidence for genetics' role in the pathogenesis of KC comes from populationbased studies: it appears that the disease is more common in certain ethnicities than in others, for instance higher incidence is observed in Indians, Pakistanis and Saudis [7]. However, environmental factors should not be ignored and their improtance should be underscored as they may induce allergic diseases of the conjunctiva and subsequent eye rubbing, which has been associated with disease progression [8]. This review will focus on non-syndromic KC, and specifically on our current understanding of the complex pathogenesis of the disease.

\footnotetext{
* Address correspondence to this author at the Departments of Medicine, Cell Biology and Ophthalmology Johns Hopkins School of Medicine, Ross 935720 Rutland Avenue, Baltimore, MD, 21205, USA; Tel: 410-502-7627; Fax: 410-614-4834; E-mail: schakra1@jhmi.edu
} 


\section{CORNEA - STRUCTURE}

The cornea is an avascular tissue that provides most of the refractive power of the eye [9]. It is composed of five layers: stratified epithelium and its basement membrane, Bowman's layer, the stroma, Descemet's membrane and the endothelium. For the purpose of this review, we will focus on the epithelium, the basement membrane, Bowman's layer, and the stroma alone as evidence strongly suggests that these layers are implicated in the pathogenesis of KC.

The human corneal epithelium is approximately 50 microns thick and consists of 4-6 layers of non-keratinized stratified squamous epithelial cells. Its basement membrane is composed mainly of collagen type IV, laminin and entactin; and the major proteoglycan is perlecan [10].

Bowman's layer is an ill-defined layer separating the epithelial basement membrane from the stroma. It is 8-12 microns thick and its collagen fibrils interweave into the stroma [9].

The stroma which comprises the bulk of the cornea is approximately 500 microns thick and is a highly ordered network of collagen fibrils and extracellular matrix. Collagen is the most common protein in the stroma, and type I collagen is the most common of these collagens. The major stromal proteoglycans are decorin, biglycan, lumican, keratocan and osteoglycin/mimecan [11].

\section{MORPHOLOGY}

All corneal layers may be affected in KC. Early histological studies and then confocal microscopy studies have shown consistent findings: epithelial changes were more apparent in severe $\mathrm{KC}$, for instance: the cells were found to be elongated or spindle shaped in severe KC patients $[12,13]$. The wing cell layer in severe $\mathrm{KC}$ had large, irregularly spaced nuclei and the mean diameter was significantly greater than in controls. Basal epithelial cells were shown to have variable changes in size compared to controls. Bowman's layer was shown to be disrupted with an occasional protrusion of epithelial cells or keratocytes as was shown in prior histological studies. Stromal findings included degraded stroma, poorly differentiated keratocyte nuclei and stromal hyper-reflectivity. The former finding may indicate loss of the quiescent phenotype of the keratocytes whereas the latter finding is consistent with apical scarring observed clinically in severe $\mathrm{KC}$ eyes. In addition, the anterior keratocyte density was confirmed to be lower using confocal microscopy [14].

Evidences for structural abnormalities have also been demonstrated in electron microscopy studies: proteoglycans were shown to be more scant in some areas of $\mathrm{KC}$ corneas and the orientation of the collagen-proteoglycan network was also abnormal with the proteoglycans oriented parallel to the collagen fibrils instead of perpendicular, reflecting an alignment pattern more similarly associated with tendons rather than the cornea [15]. In an X-ray diffraction study, the mean collagen interfibrillar space in $\mathrm{KC}$ was shown to be similar to normal control corneas, so the hallmark finding of $\mathrm{KC}$ - apical stromal thinning - was not attributed to packing of the fibrils in the corneal apex but to fibril loss [16]. Another important finding from that study was that the fibril diameter was similar in both $\mathrm{KC}$ and controls, so changes in the size of the collagen fibril do not account for $\mathrm{KC}$ phenotype. An additional X-ray diffraction study demonstrated loss of normal orthogonal (peripheral) or isotropic (central) lamellar architecture in KC [17]. The abnormality in collagen organization was later shown to be present in both the anterior and posterior parts of the cornea, especially in the area of maximal steepening [18]. These changes may account for the biomechanical instability and weakening that are hallmarks of $\mathrm{KC}$, especially because the anterior stroma confers the majority of the biomechanical strength to the cornea [19 - 23]. Interestingly, a mid-stromal transplantation of isolated Bowman layer was recently suggested as a method to flatten the anterior cornea in advanced $\mathrm{KC}[24,25]$.

\section{MOLECULAR CHANGES}

\subsection{Protein Changes in $\mathrm{KC}$}

Protein studies of keratoconus originate in the 1980s: these early studies that used SDS-PAGE electrophoresis showed that corneas inflicted with $\mathrm{KC}$ have a reduced amount of collagen [26]. A prior immunohistochemistry study had shown decreased staining of Collagen type XII [27]. However, these analytical methods were not perfectly capable to identify all types of collagen involved in the disease process. This problem was solved with contemporary proteomic studies that have shown specific decreases in collagens type XII, I and V. [28, 27]

Additional earlier evidence suggested that the culprit in $\mathrm{KC}$ is perhaps collagen degradation due to over-expression of gelatinases [29 - 32]. Other relatively recent studies also indicate elevated proteolytic activity in KC corneas. In one 
report, there was a 2.2 fold increase in mRNA of catalase, 1.8 fold increase in enzyme activity and a 1.8 fold decrease in tissue inhibitor of matrix metalloproteinase (TIMP)-1 [33]. Another recent report has shown increased tear expression of MMP-1,-3,-7, and -13 in $\mathrm{KC}$ compared to controls [34]. An interesting observation made by this study was that gelatinolytic and collagenolytic activity in $\mathrm{KC}$ patients was elevated compared to controls, but when the $\mathrm{KC}$ group was compared to KC patients who underwent corneal collagen cross-linking (CXL) - there was no difference. This suggests that cross-linking does not change the biology of the disease, but only induces tissue resistance to degradation, as expected. An additional study demonstrated that eye rubbing, which has been linked to disease progression in $\mathrm{KC}$, can by itself cause an elevation in the tear concentrations of MMP-13 [35]. This could theoretically provide the explanation as to why stromal thinning progresses in $\mathrm{KC}$ patients who frequently rub their eyes. Despite this evidence for increased expression of proteolytic enzymes in $\mathrm{KC}$, it is difficult to determine whether proteolytic activity is a primary defect in the disease or whether it reflects ongoing tissue repair and remodeling which is also associated with expression of proteolytic enzymes.

Other studies on molecular changes have suggested that inflammation may play a role in $\mathrm{KC}$ despite the fact that clinically, KC does not appear to be an inflammatory eye disease. In a pilot study that used ELISA techniques KC patients were shown to have elevated IL-6 and TNF- $\alpha$ compared to healthy controls [36]. Our group studied the tears of KC patients using a highly sensitive multiplex immune-bead assay [37]. This study demonstrated a significant reduction in the concentrations of IL-12, CCL5 and TNF- $\alpha$ in KC patients. Although not statistically significant, IL-6 levels were also elevated. Additionally, a trend was observed for elevation in IL-17. The development of highly sensitive mass spectrometry has made it possible to examine global differences in protein levels: mass spectrometry on proteins extracted from tear fluid indicated that $\mathrm{KC}$ patients have lower levels of zinc- $\alpha 2$-glycoprotein, immunoglobulin kappa chain and lactoferrin [38]. The latter is of particular interest because lactoferrin is thought to exert antimicrobial and anti-inflammatory effects, however lactoferrin levels have been shown to be reduced in numerous ocular surface diseases, such as: dry eye and contact lens induced papillary conjunctivitis [39]. Many KC patients are also contact lens users, and therefore the significance of the finding of reduced lactoferrin in $\mathrm{KC}$ remains unclear. An additional mass spectrometric proteomic study showed that MMP-1 was present only in KC subjects, contrary to healthy controls. $[40,37]$ A similar study from another group confirmed some of these findings: a recent cytokine microarray analysis study showed increased tear levels of IL-4, -5, -6, -8 and TNF-a in KC compared to controls [34]. IL-6 was the only cytokine significantly increased in $\mathrm{KC}$ when compared with the cross-linked (CXL) group. The CXL group had no change in proteases but had elevaed TNF- $\alpha$ compared to the control group.

The first proteomic study on the keratoconus cornea was performed on epithelial specimens alone [41]. The most dramatic changes were observed in the concentration of the epithelial differentiation marker cytokeratin 3 (KRT3) when compared to controls. Other proteins found in excess in KC were S100A4 and gelsolin; enolase 1 was down-regulated in KC. These are largely cytoskeleton-associated proteins. S100A4 is a calcium binding protein that can bind to multiple elements of the cytoskeleton. It stimulates cell migration and change in cell morphology. Gelsolin caps actin during its assembly. It is known to stimulate cell motility and has been linked to apoptosis. Enolase 1 that is mainly produced in the basal epithelial cells was reduced in $\mathrm{KC}$, which suggests de-differentiation or a decreased proliferation of the basal cells. However, enolase 1 also has a role in glycolysis and in adhesion to the ECM [42, 43]. As a whole, these findings suggest that a cytoskeletal and/or cytoskeletal associated cell-to-cell or cell-to-ECM system may be faulty in $\mathrm{KC}$ corneal epithelium.

Additional evidence confirmed the findings of reduced enolase 1 production in the epithelium of KC cornea [44] The study also showed that the same was true for $\beta$-actin. Western blot analysis demonstrated broken fragments of these proteins that suggested protein degradation in $\mathrm{KC}$, consistent with the above-mentioned findings of increased proteolysis in KC. As noted above, enolase 1 is a marker for epithelial basal cells and stem cells. The finding of enolase 1 downregulation in $\mathrm{KC}$ alludes to failure to repopulate the epithelial layer.

Another proteomic study of the corneal epithelium in $\mathrm{KC}$ demonstrated higher levels of lamin-A/C, keratin type I cytoskeletal 14 and 16, tubulin beta chain, heat shock protein cognate 71kDA protein, and S100-A4 [45]. Other findings were lower levels of transketolase, phosphoglycerate kinase 1, NADPH dehydrogenase 1, and 14-3-3 protein sigma. The latter is a protein involved in cellular signaling and interaction; cell cycle; cytoskeletal structure and intracellular trafficking [46]. In our iTRAQ mass spectrometric study of the cornea, the main epithelial proteins found to be increased were keratins $(6 \mathrm{~A}, 16)$, beta-hemoglobin, S100 calcium binding protein A8, calmodulin-like 3 protein, and others. [28] Vimentin, a marker of myofibroblastic transformation and epithelial to mesenchymal transformation during wound repair, was found to be increased. Significant decreases were observed in collagen type VI, a major structural 
component of microfibrils, lactotransferrin, cAMP-regulated phosphoprotein, collagen type VII alpha1 and collagen type XII that help to anchor epithelial cells to the underlying matrix, heparan sulfate proteoglycan 2 and others. Taken together, these observations underscore a structural cytoskeletal or a cell-basement membrane adhesion defect in the corneal epithelium in the disease process.

Given that the main clinically observable defect in $\mathrm{KC}$ is the thinning of the stroma, proteomic studies of $\mathrm{KC}$ stroma were warranted. In the same study described above, our group yielded the most comprehensive proteomic landscape of the keratoconic corneal stroma, identifying a total of 1,157 proteins. Decreases were detected in many structural extracellular matrix proteins of the corneal stroma such as, decorin, lumican and keratocan, collagen types I and V [28]. Decorin, lumican and keratocan are stromal proteoglycans that variably regulate collagen fibril structure, corneal transparency and thickness [47 - 49]. In addition, there were decreases in corneal crystallins that contribute to cellular transparency in the healthy cornea [50]. Elevated proteins in the stroma included adaptor-related protein complex 2 (AP2B1), immunoglobulin Lambda-like polypeptide 1(IGLL1), cell division cycle and apoptosis regulator 1 (CCAR1) and other regulators of cell cycle. These changes are consistent with altered cell proliferation and apoptosis-related programs. In addition, a large number of ribosomal proteins were elevated that suggest endoplasmic stress and perturbation of events during translation.

The cumulative proteomic findings suggest a generalized loss of the normal quiescent phenotype of the keratocytes and an increase in the abnormal protein expression, similarly to that associated with wound healing phenotype. The global decrease in different types of collagens is consistent with the clinical observation of debulked and thinned corneas in $\mathrm{KC}$.

The aqueous humor provides nutrients to the posterior avascular cornea and has been recently studied by mass spectrometry [51]. Samples obtained from patients with keratoconus were also analyzed and revealed significant differences compared to controls [52]. Hemoglobin subunit beta, haptoglobin, plasma protease C1 inhibitor, basement membrane-specific heparin sulfate proteoglycan core protein, hemoglobin subunit delta, carbonic anhydrase 1 (and others) were all over-expressed in KC samples. Ceruloplasmin, apolipoprotein A2, actin cytoplasmic 2, latent transforming growth factor beta-binding protein 2 and Ig kappa chain V-I region EU as well as others were underexpressed. These findings underscore the complexity of $\mathrm{KC}$ and the diversity of proteomic findings in different studies.

\section{PATHWAYS INVOLVED IN KC - HYPOTHESES}

In view of the evidence obtained from proteomic studies, the involvement of a few potential pathways may be hypothesized:

\subsection{Cytokine Dysregulation}

Inflammatory cytokines have been shown to be over-expressed in KC. Our group has shown IL-17 over-expression in pooled samples from KC patients. Interestingly, the corneal epithelium is one of the targets of IL-17 and when human corneal epithelial cells lines are exposed to stress they can produce cytokines that promote Th-17 differentiation [53]. Despite this known association, it remains unclear whether it is pro-inflammatory cytokines that trigger the cascade that leads to the typical phenotype that we call $\mathrm{KC}$ or a dysregulated $\mathrm{Th} 1, \mathrm{Th} 2$ and $\mathrm{Th} 17$ response as suggested by our tear cytokine study [37].

\subsection{Oxidative Stress}

Oxidative stress has long been implicated in the pathogenesis of KC [54 - 57]. However, it was not until 2005 that elevated catalase RNA and activity were demonstrated in human KC corneas [33]. Catalase is the major pathway through which the cells dispose of excess hydrogen peroxide. Additional observations from that study included upregulations of numerous types of cathepsins, which by themselves can promote hydrogen peroxide formation, thereby feeding the oxidative cycle. This overall pro-oxidative environment was hypothesized to trigger the tissue destruction seen in KC. Additional evidence from recent studies provides more support of the hypothesis that oxidative stress may play a significant role in KC. A study of keratoconus corneas assessed their antioxidant capacity, nitrites, lipid peroxidation products and other oxidative stress markers [58]. Both KC and post-LASIK ectatic corneas had signs of elevated oxidative stress when compared to healthy controls, a finding consistent with prior studies in the field of KC. Another recent tear metabolite study has also shown that the ratio of lactate to pyruvate, a marker for oxidative stress, is elevated in $\mathrm{KC}$ [59]. Moreover, the ratio of reduced to oxidized glutathione was elevated in $\mathrm{KC}$, which also supports the 
theory that oxidative stress plays a role in KC. Gene ontology analysis of that study suggested that oxidative stress may be the underlying mechanism that triggers apoptosis in $\mathrm{KC}$. This may be a missing link between oxidative stress and keratocyte apoptosis that has been reported to occur in $\mathrm{KC}$, particularly as the cornea is exposed to high levels of oxidative stress (atmospheric $\mathrm{O}_{2}$ levels and ambient ultraviolet irradiation).

\subsection{Alterations in TGF- $\beta$ and the Effect on The Extracellular Matrix (ECM)}

The ECM is produced by keratocytes. This process is regulated, amongst others, by TGF- $\beta$ signaling [60, 61] Not surprisingly, a known systemic disease, Marfan syndrome, which is associated with TGF- $\beta$ pathway mutations may also manifest with $\mathrm{KC}$ [62] Other anterior segment pathologies besides $\mathrm{KC}$ have been described to occur more commonly in patients with Marfan syndrome, namely: megalocornea, corneal flattening or scleral thinning. The analogy of the aortic wall thinning and dilatation seen in Marfan syndrome and the corneal stromal thinning seen in $\mathrm{KC}$ is imperfect, but the association is enticing [63 - 67].

Two reports from our group have shown that the TGF- $\beta$ axis may be dysfunctional in keratoconus. An immunohistochemical staining showed increased pSMAD 2 staining of the keratoconus corneal epithelium. In the second, cultured stromal cells from keratoconus corneas showed an abnormally increased phosphorylation of pSMAD1/5/8 - a signaling axis that is novel to the cornea [68, 69]. Another well recognized fact is that different isoforms of TGF- $\beta$ have distinct effects on the extracellular matrix, but in one study an aberrant TGF- $\beta 1$ response was noted in human keratoconus cell lines deployed in a 3D collagen gel [70]. In that study, increased ECM contraction and overexpression of collagen I and V were observed. An additional study demonstrated that some of the downstream messengers in the TGF- $\beta$ axis may be abnormal in keratoconus: KC keratocyte cell lines had downregulated expression of SMAD6 and SMAD7 when compared to normal keratocyte cell lines [71]. Moreover, that study showed that the expression patterns of these secondary messengers were left unchanged despite stimulation with TGF- $\beta$ isoforms, which in normal cells produced a more robust response. In a different study, human corneal stromal fibroblasts exposed to various isoforms of TGF- $\beta$ demonstrated a differential fibrotic response, especially in cells exposed to TGF- $\beta 3$, an isoform known for its anti-fibrosis properties [72]. If a similar response could be elicited in vivo, this may be a therapeutic target to prevent stromal scarring which is often observed in severe $\mathrm{KC}$ cases.

Altogether, these findings suggest that the TGF- $\beta$ pathway may be an important effector route in $\mathrm{KC}$ and warrant further research.

\section{CELLULAR RESPONSES IN KC}

The hypothesis that the trigger for keratoconus lies in the epithelium was stipulated a few decades ago. The corneal epithelial basement membrane was shown to be irregular or absent in cases of severe KC using anti collagen type IV antibodies [73]. An abnormal architecture of the interface between the basal cell layer of the epithelium and the underlying stroma was demonstrated in $\mathrm{KC}$ corneas and specifically, the epithelium-stromal interface of the central cornea mirrored that of the normal limbal area [74]. Diminished collagen XII staining was demonstrated at the level of the epithelial basement membrane in $\mathrm{KC}$ corneas, a finding that was later confirmed in a proteomic study of $\mathrm{KC}$ $[27,28]$. Collagen type XII is believed to anchor the epithelial layer to the underlying stroma. This evidence of epithelial-stromal interface abnormalities in $\mathrm{KC}$ does not by itself explain the classic corneal stromal thinning seen in $\mathrm{KC}$, however, animal models of corneal epithelial injury demonstrated apoptosis of the underlying stromal keratocytes [75 - 77]. Keratocytes produce the ECM of the corneal stroma, but their phenotype is exquisitely dependent on their isolation from the environment, which may only be $60 \mu \mathrm{m}$ away. It is well understood that keratocytes are primed to apoptose upon insult to injury. This is hypothesized to be a mechanism to limit spread of viruses or other infections. If the area directly above the keratocytes is constantly depleted of barrier function due to lack of epithelial cells this may be sufficient to elucidate the apoptotic response of the keratocytes, contributing to loss of cell number. Subsequently an area persistently depleted of keratocytes may have collagen drop-out over time.

Keratocytes are specialized tissue fibroblasts that reside within the corneal stroma and produce most of the corneal stromal proteins $[78-80]$. In KC, keratocyte density is lower than in healthy controls. The role of keratocytes is to maintain the highly ordered extracellular matrix (ECM) of the corneal stroma, mainly: collagens I, III, V; the proteoglycans: keratocan, lumican and decorin as well as other proteins [11]. These ECM components, when properly arranged maintain a structurally stable cornea that is optically clear and possesses the desired refractive and biomechanical properties. For these reasons, keratocytes are likely to be implicated in $\mathrm{KC}$, and their study in tissue cultures may be pivotal to the study of KC. However, when grown in culture keratocytes soon lose their corneal in situ 
morphology and transform into their fibroblastic phenotype unless grown in serum free media - then they remain dendritic and quiescent $[11,81]$.

Multiple in vivo confocal scanning microscopy studies have shown that keratocyte density in KC is lower than in normal subjects $[14,82,83]$. Keratocyte depletion in $\mathrm{KC}$ was reported to be the result of apoptosis, as shown by TUNEL immunohistochemistry staining of KC corneas [84]. This finding was later strengthened by a gene expression study that demonstrated differential expression of apoptosis genes in $\mathrm{KC}$ derived keratocytes, however the culture media in which the keratocytes were grown was rich in serum. Therefore, a potential bias is of concern, as the keratocytes may have assumed a fibroblastic phenotype typical for keratocytes grown in such conditions [85].

Our studies of keratocytes in culture also point to dysregulations of the TGF $\beta$ pathway in keratoconus. Additional studies are required to pinpoint alterations in specific intermediates in TGF $\beta$ signal propagations in KC keratocytes.

\section{DISCUSSION}

Overall, it appears that KC may be caused by an aberrant tissue response to one or more unidentified stimuli that subsequently leads to keratocyte depletion or dysfunction, loss of collagen, and ultimately a biomechanically weak cornea with a degenerated ECM.

\section{CONCLUSION}

Despite major leaps in methodology, the origin and pathogenesis of $\mathrm{KC}$ remain elusive. The findings of various studies are sometimes so dissimilar that their comparison and juxtaposition become quite challenging. The fact that $\mathrm{KC}$ is a spectrum of phenotypes ranging from mild to severe vision disabling disease does not simplify the researcher's task either. Naturally, studies performed on end-stage cases are less likely to demonstrate similar findings as in early and active disease - which may explain some of the heterogeneity in the findings of different studies. Other factors that need to be considered are that the disease itself may be multifactorial - caused by multiple genetic mutations; it may be affected by environmental factors such as climate and geography; and it may also be the final phenotype or pathway of multiple processes occurring simultaneously at the level of the epithelium and the stroma. Ultimately research on keratoconus is striving to identify these multiple-gene environment interactions to better understand disease processes in individual patients and tailored care.

\section{CONSENT FOR PUBLICATION}

Not applicable.

\section{CONFLICT OF INTEREST}

The author (editor) declares no conflict of interest, financial or otherwise.

\section{ACKNOWLEDGEMENTS}

This review was supported by NEI-R01 EY026104.

\section{REFERENCES}

[1] Klintworth GK, Damms T. Corneal dystrophies and keratoconus. Curr Opin Ophthalmol 1995; 6(4): 44-56. [http://dx.doi.org/10.1097/00055735-199508000-00009] [PMID: 10150882]

[2] Rabinowitz YS. Keratoconus. Surv Ophthalmol 1998; 42(4): 297-319. [http://dx.doi.org/10.1016/S0039-6257(97)00119-7] [PMID: 9493273]

[3] Rahi A, Davies P, Ruben M, Lobascher D, Menon J. Keratoconus and coexisting atopic disease. Br J Ophthalmol 1977; 61(12): 761-4. [http://dx.doi.org/10.1136/bjo.61.12.761] [PMID: 603783]

[4] Lu Y, Vitart V, Burdon KP, et al. Genome-wide association analyses identify multiple loci associated with central corneal thickness and keratoconus. Nat Genet 2013; 45(2): 155-63. [http://dx.doi.org/10.1038/ng.2506] [PMID: 23291589]

[5] Hameedaldeen A, Liu J, Batres A, Graves GS, Graves DT. FOXO1, TGF- $\beta$ regulation and wound healing. Int J Mol Sci 2014; 15(9): 16257-69.

[http://dx.doi.org/10.3390/ijms150916257] [PMID: 25226535]

[6] Wang Y, Rabinowitz YS, Rotter JI, Yang H. Genetic epidemiological study of keratoconus: evidence for major gene determination. Am J Med Genet 2000; 93(5): 403-9.

[http://dx.doi.org/10.1002/1096-8628(20000828)93:5<403::AID-AJMG11>3.0.CO;2-A] [PMID: 10951465] 
[7] Kok YO, Tan GF, Loon SC. Review: keratoconus in Asia. Cornea 2012; 31(5): 581-93. [http://dx.doi.org/10.1097/ICO.0b013e31820cd61d] [PMID: 22314815]

[8] Cingu AK, Cinar Y, Turkcu FM, et al. Effects of vernal and allergic conjunctivitis on severity of keratoconus. Int J Ophthalmol 2013; 6(3): $370-4$. [http://dx.doi.org/10.3980/j.issn.2222-3959.2013.03.21] [PMID: ijo-06-03-370]

[9] Eghrari AO, Riazuddin SA, Gottsch JD. Overview of the cornea: structure, function, and development. Prog Mol Biol Transl Sci 2015; 134: 7-23. [http://dx.doi.org/10.1016/bs.pmbts.2015.04.001] [PMID: 26310146]

[10] Dietrich-Ntoukas T, Hofmann-Rummelt C, Kruse FE, Schlötzer-Schrehardt U. Comparative analysis of the basement membrane composition of the human limbus epithelium and amniotic membrane epithelium. Cornea 2012; 31(5): 564-9. [http://dx.doi.org/10.1097/ICO.0b013e3182254b78] [PMID: 22382594]

[11] Hassell J R, Birk D E. The molecular basis of corneal transparency. Exp Eye Res 2010; 91: 326-35. [http://dx.doi.org/S0014-4835(10)00192-2] [PMID: 10.1016/j.exer.2010.06.021 (201)]

[12] Hollingsworth J G, Bonshek R E, Efron N. Correlation of the appearance of the keratoconic cornea in vivo by confocal microscopy and in vitro by light microscopy. Cornea 2005; 24: 397-405. [http://dx.doi.org/00003226-200505000-00005]

[13] Hollingsworth J G, Efron N. Observations of banding patterns (Vogt striae) in keratoconus: A confocal microscopy study. Cornea 2005; 24: $162-6$. [http://dx.doi.org/00003226-200503000-00007]

[14] Hollingsworth JG, Efron N, Tullo AB. In vivo corneal confocal microscopy in keratoconus. Ophthalmic Physiol Opt 2005; 25: 254-60. [http://dx.doi.org/10.1111/j.1475-1313.2005.00278.x]

[15] Fullwood NJ, Meek KM, Malik NS, Tuft SJ. A comparison of proteoglycan arrangement in normal and keratoconus human corneas. Biochem Soc Trans 1990; 18(5): 961-2. [http://dx.doi.org/10.1042/bst0180961] [PMID: 1707381]

[16] Fullwood NJ, Tuft SJ, Malik NS, Meek KM, Ridgway AE, Harrison RJ. Synchrotron x-ray diffraction studies of keratoconus corneal stroma. Invest Ophthalmol Vis Sci 1992; 33(5): 1734-41. [PMID: 1559773]

[17] Meek KM, Stephen JT, Yifei H, et al. Changes in collagen orientation and distribution in keratoconus corneas. Invest Ophthalmol Vis Sci 2005; 46: 1948-56. [http://dx.doi.org/10.1167/iovs.04-1253]

[18] Hayes S, Khan S, Boote C, et al. Depth profile study of abnormal collagen orientation in keratoconus corneas. Arch Ophthalmol 2012; 130: 251-2. [http://dx.doi.org/10.1001/archopthalmol.2011.1467]

[19] Bron AJ. The architecture of the corneal stroma. Br J Ophthalmol 2001; 85(4): 379-81. [http://dx.doi.org/10.1136/bjo.85.4.379] [PMID: 11264120]

[20] Dias JM, Ziebarth NM. Anterior and posterior corneal stroma elasticity assessed using nanoindentation. Exp Eye Res 2013; 115 : 41-6. [http://dx.doi.org/10.1016/j.exer.2013.06.004] [PMID: 23800511]

[21] Müller LJ, Pels E, Vrensen GF. The specific architecture of the anterior stroma accounts for maintenance of corneal curvature. Br J Ophthalmol 2001; 85(4): 437-43. [http://dx.doi.org/10.1136/bjo.85.4.437] [PMID: 11264134]

[22] Petsche SJ, Pinsky PM. The role of 3-D collagen organization in stromal elasticity: a model based on X-ray diffraction data and second harmonic-generated images. Biomech Model Mechanobiol 2013; 12(6): 1101-13. [http://dx.doi.org/10.1007/s10237-012-0466-8] [PMID: 23288406]

[23] Last JA, Thomasy SM, Croasdale CR, Russell P, Murphy CJ. Compliance profile of the human cornea as measured by atomic force microscopy. Micron 2012; 43(12): 1293-8 [http://dx.doi.org/10.1016/j.micron.2012.02.014] [PMID: 22421334]

[24] van Dijk K, Parker J, Tong CM, et al. Midstromal isolated Bowman layer graft for reduction of advanced keratoconus: a technique to postpone penetrating or deep anterior lamellar keratoplasty. JAMA Ophthalmol 2014; 132(4): 495-501. [http://dx.doi.org/10.1001/jamaophthalmol.2013.5841] [PMID: 24557359]

[25] van Dijk K, Liarakos VS, Parker J, et al. Bowman layer transplantation to reduce and stabilize progressive, advanced keratoconus. Ophthalmology 2015; 122(5): 909-17. [http://dx.doi.org/10.1016/j.ophtha.2014.12.005] [PMID: 25596620]

[26] Critchfield JW, Calandra AJ, Nesburn AB, Kenney MC. Keratoconus: I. Biochemical studies. Exp Eye Res 1988; 46(6): 953-63. [http://dx.doi.org/10.1016/S0014-4835(88)80047-2] [PMID: 3197764]

[27] Cheng EL, Maruyama I, SundarRaj N, Sugar J, Feder RS, Yue BY. Expression of type XII collagen and hemidesmosome-associated proteins in keratoconus corneas. Curr Eye Res 2001; 22(5): 333-40. [http://dx.doi.org/10.1076/ceyr.22.5.333.5491] [PMID: 11600933] 
[28] Chaerkady R, Shao H, Scott S G, et al. The keratoconus corneal proteome: Loss of epithelial integrity and stromal degeneration. J Proteomics 2013; 87: 122-31. [http://dx.doi.org/S1874-3919(13)00264-9] [PMID: 10.1016/j.jprot.2013.05.023]

[29] Fini ME, Yue BY, Sugar J. Collagenolytic/gelatinolytic metalloproteinases in normal and keratoconus corneas. Curr Eye Res 1992; 11(9): 849-62. [http://dx.doi.org/10.3109/02713689209033483] [PMID: 1424728]

[30] Kao WW, Vergnes JP, Ebert J, Sundar-Raj CV, Brown SI. Increased collagenase and gelatinase activities in keratoconus. Biochem Biophys Res Commun 1982; 107: 929-36. [pii] [http://dx.doi.org/0006-291X(82)90612-X]

[31] Ihalainen A, Salo T, Forsius H, Peltonen L. Increase in type I and type IV collagenolytic activity in primary cultures of keratoconus cornea. Eur J Clin Invest 1986; 16(1): 78-84. [http://dx.doi.org/10.1111/j.1365-2362.1986.tb01311.x] [PMID: 3009200]

[32] Zhou L, Yue BY, Twining SS, Sugar J, Feder RS. Expression of wound healing and stress-related proteins in keratoconus corneas. Curr Eye Res 1996; 15(11): 1124-31. [http://dx.doi.org/10.3109/02713689608995144] [PMID: 8950507]

[33] Kenney MC, Chwa M, Atilano SR, et al. Increased levels of catalase and cathepsin V/L2 but decreased TIMP-1 in keratoconus corneas: evidence that oxidative stress plays a role in this disorder. Invest Ophthalmol Vis Sci 2005; 46(3): 823-32. [http://dx.doi.org/46/3/823]

[34] Balasubramanian SA, Mohan S, Pye DC, Willcox MD. Proteases, proteolysis and inflammatory molecules in the tears of people with keratoconus. Acta Ophthalmol 2012; 90(4): e303-9. [http://dx.doi.org/10.1111/j.1755-3768.2011.02369.x] [PMID: 22413749]

[35] Balasubramanian SA, Pye DC, Willcox MD. Effects of eye rubbing on the levels of protease, protease activity and cytokines in tears: relevance in keratoconus. Clin Exp Optom 2013; 96(2): 214-8. [http://dx.doi.org/10.1111/cxo.12038] [PMID: 23496656]

[36] Lema I, Duran J A. Inflammatory molecules in the tears of patients with keratoconus. Ophthalmology 2005; 112: 654-9. [http://dx.doi.org/10.1016/j.ophtha.2004.11.050]

[37] Jun AS, Cope L, Speck C, et al. Subnormal cytokine profile in the tear fluid of keratoconus patients. PLoS One 2011; 6(1): e16437. [http://dx.doi.org/10.1371/journal.pone.0016437] [PMID: 21298010]

[38] Lema I, Brea D, Rodríguez-González R, Díez-Feijoo E, Sobrino T. Proteomic analysis of the tear film in patients with keratoconus. Mol Vis 2010; 16: 2055-61. [PMID: 21042560]

[39] Flanagan JL, Willcox MD. Role of lactoferrin in the tear film. Biochimie 2009; 91(1): 35-43. [http://dx.doi.org/10.1016/j.biochi.2008.07.007] [PMID: 18718499]

[40] Pannebaker C, Chandler H L, Nichols J J. Tear proteomics in keratoconus. Mol Vis 2010; 16: 1949-57. [PMID: 21031023]

[41] Nielsen K, Vorum H, Fagerholm P, et al. Proteome profiling of corneal epithelium and identification of marker proteins for keratoconus, a pilot study. Exp Eye Res 2006; 82: 201-9.

[PMID: 16083875] [http://dx.doi.org/10.1016/j.exer.2005.06.009]

[42] Walsh JL, Knull HR. Heteromerous interactions among glycolytic enzymes and of glycolytic enzymes with F-actin: effects of poly(ethylene glycol). Biochim Biophys Acta 1988; 952(1): 83-91. [http://dx.doi.org/10.1016/0167-4838(88)90104-5] [PMID: 3334856]

[43] Pratesi F, Moscato S, Sabbatini A, Chimenti D, Bombardieri S, Migliorini P. Autoantibodies specific for alpha-enolase in systemic autoimmune disorders. J Rheumatol 2000; 27(1): 109-15. [PMID: 10648026]

[44] Srivastava OP, Chandrasekaran D, Pfister RR. Molecular changes in selected epithelial proteins in human keratoconus corneas compared to normal corneas. Mol Vis 2006; 12: 1615-25.

[http://dx.doi.org/v12/a185 [pii]]

[45] Joseph R, Srivastava O P, Pfister R R. Differential epithelial and stromal protein profiles in keratoconus and normal human corneas. Exp Eye Res 2011; 92(4): 282-98. [http://dx.doi.org/10.1016/j.exer.2011.01.008]

[46] Aitken A. 14-3-3 proteins: A historic overview. Semin Cancer Biol 2006; 16(3): 162-72. [http://dx.doi.org/10.1016/j.semcancer.2006.03.005] [PMID: 16678438]

[47] Chen S, Birk DE. Focus on molecules: decorin. Exp Eye Res 2011; 92(6): 444-5. [http://dx.doi.org/10.1016/j.exer.2010.05.008] [PMID: 20493188]

[48] Zhang G, Chen S, Goldoni S, et al. Genetic evidence for the coordinated regulation of collagen fibrillogenesis in the cornea by decorin and biglycan. J Biol Chem 2009; 284(13): 8888-97. [http://dx.doi.org/M806590200 [pii]] 
[49] Chakravarti S, Magnuson T, Lass JH, Jepsen KJ, LaMantia C, Carroll H. Lumican regulates collagen fibril assembly: skin fragility and corneal opacity in the absence of lumican. J Cell Biol 1998; 141(5): 1277-86. [http://dx.doi.org/10.1083/jcb.141.5.1277] [PMID: 9606218]

[50] Piatigorsky J. Enigma of the abundant water-soluble cytoplasmic proteins of the cornea: the "refracton" hypothesis. Cornea 2001; 20(8): 853-8. [http://dx.doi.org/10.1097/00003226-200111000-00015] [PMID: 11685065]

[51] Murthy KR, Rajagopalan P, Pinto SM, et al. Proteomics of human aqueous humor. OMICS 2015; 19(5): 283-93. [http://dx.doi.org/10.1089/omi.2015.0029] [PMID: 25933257]

[52] Soria J, Villarrubia A, Merayo-Lloves J, et al. Label-free LC-MS/MS quantitative analysis of aqueous humor from keratoconic and normal eyes. Mol Vis 2015; 21: 451-60. [PMID: 25999673]

[53] Zheng X, de Paiva C S, Li D Q, Farley W J, Pflugfelder S C. Desiccating stress promotion of Th17 differentiation by ocular surface tissues through a dendritic cell-mediated pathway. Invest Ophthalmol Vis Sci 2010; 51: 3083-91. [PMID: 25999673] [http://dx.doi.org/10.1167/iovs.09-3838]

[54] Behndig A, Karlsson K, Johansson BO, Brännström T, Marklund SL. Superoxide dismutase isoenzymes in the normal and diseased human cornea. Invest Ophthalmol Vis Sci 2001; 42(10): 2293-6. [PMID: 11527942]

[55] Buddi R, Lin B, Atilano SR, Zorapapel NC, Kenney MC, Brown DJ. Evidence of oxidative stress in human corneal diseases. J Histochem Cytochem 2002; 50(3): 341-51.

[http://dx.doi.org/10.1177/002215540205000306] [PMID: 11850437]

[56] Gondhowiardjo TD, van Haeringen NJ. Corneal aldehyde dehydrogenase, glutathione reductase, and glutathione S-transferase in pathologic corneas. Cornea $1993 ; 12(4): 310-4$ [http://dx.doi.org/10.1097/00003226-199307000-00006] [PMID: 8339559]

[57] Gondhowiardjo TD, van Haeringen NJ, Völker-Dieben HJ, et al. Analysis of corneal aldehyde dehydrogenase patterns in pathologic corneas. Cornea 1993; 12(2): 146-54. [http://dx.doi.org/10.1097/00003226-199303000-00010] [PMID: 8500322]

[58] Arnal E, Peris-Martinez C, Menezo JL, Johnsen-Soriano S, Romero FJ. Oxidative stress in keratoconus? Invest Ophthalmol Vis Sci 2011; 52: $8592-7$

[http://dx.doi.org/10.1167/iovs.11-7732]

[59] Karamichos D, Zieske JD, Sejersen H, Sarker-Nag A, Asara JM, Hjortdal J. Tear metabolite changes in keratoconus. Exp Eye Res 2015; 132: $1-8$. [http://dx.doi.org/10.1016/j.exer.2015.01.007] [PMID: 25579606]

[60] Chen S, Mienaltowski MJ, Birk DE. Regulation of corneal stroma extracellular matrix assembly. Exp Eye Res 2015; 133: 69-80. [http://dx.doi.org/10.1016/j.exer.2014.08.001] [PMID: 25819456]

[61] Massague J. TGFbeta signalling in context. Nat Rev Mol Cell Biol 2012; 13: 616-30. [http://dx.doi.org/nrm3434 [pii] 0.1038/nrm3434]

[62] Akhurst R J. TGF beta signaling in health and disease. Nat Genet 2004; 36: 790-630. [http://dx.doi.org/nrm3434 [pii] 0.1038/nrm3434]

[63] Dietz H C. TGF-beta in the pathogenesis and prevention of disease: a matter of aneurysmic proportions. J Clin Invest 2010; 120 : $403-7$. [http://dx.doi.org/42014 [pii]10.1172/JCI42014]

[64] Holm TM, Habashi JP, Doyle JJ, et al. Noncanonical TGFbeta signaling contributes to aortic aneurysm progression in Marfan syndrome mice. Science $2011 ; 332: 358-61$.

[http://dx.doi.org/332/6027/358 [pii]10.1126/science.1192149]

[65] Boileau C, Guo DC, Hanna N, et al. TGFB2 mutations cause familial thoracic aortic aneurysms and dissections associated with mild systemic features of Marfan syndrome. Nature Genet 2012; 44(8): 916-21. [http://dx.doi.org/10.1038/ng.2348]

[66] Doyle AJ, Doyle JJ, Bessling SL, et al. Mutations in the TGF-beta repressor SKI cause Shprintzen-Goldberg syndrome with aortic aneurysm. Nature Genet 2012; 44: 1249-54. [http://dx.doi.org/.2421 [pii]10.1038/ng.2421]

[67] Haskett D, Doyle JJ, Gard C, et al. Altered tissue behavior of a non-aneurysmal descending thoracic aorta in the mouse model of Marfan syndrome. Cell Tissue Res 2012; 347(1): 267-77. [http://dx.doi.org/10.1007/s00441-011-1270-y] [PMID: 22105919]

[68] Engler C, Chakravarti S, Doyle J, et al. Transforming growth factor-beta signaling pathway activation in Keratoconus. Am J Ophthalmol 2011; 151(5): 759-e752. [http://dx.doi.org/S0002-9394(10)00903-7] [http://dx.doi.org/[pii]10.1016/j.ajo.2010.11.008]

[69] Foster J, Wu WH, Scott SG, et al. Transforming growth factor $\beta$ and insulin signal changes in stromal fibroblasts of individual keratoconus patients. PLoS One 2014; 9(9): e106556. 
[http://dx.doi.org/10.1371/journal.pone.0106556] [PMID: 25247416]

[70] Lyon D, McKay TB, Sarkar-Nag A, Priyadarsini S, Karamichos D. Human Keratoconus Cell Contractility is Mediated by Transforming Growth Factor-Beta Isoforms. J Funct Biomater 2015; 6(2): 422-38.

[http://dx.doi.org/10.3390/jfb6020422] [PMID: 26096146]

[71] Priyadarsini S, McKay TB, Sarker-Nag A, Karamichos D. Keratoconus in vitro and the key players of the TGF- $\beta$ pathway. Mol Vis 2015; 21 : 577-88.

[PMID: 26015770]

[72] Karamichos D, Hutcheon AE, Zieske JD. Transforming growth factor- $\beta 3$ regulates assembly of a non-fibrotic matrix in a $3 \mathrm{D}$ corneal model. J Tissue Eng Regen Med 2011; 5(8): e228-38. [http://dx.doi.org/10.1002/term.429] [PMID: 21604386]

[73] Newsome DA, Foidart JM, Hassell JR, et al. Detection of specific collagen types in normal and keratoconus corneas. Invest Ophthalmol Vis Sci 1981; 20(6): 738-50. [PMID: 7016805]

[74] Ebihara N, Watanabe Y, Nakayasu K, Kanai A. The expression of laminin-5 and ultrastructure of the interface between basal cells and underlying stroma in the keratoconus cornea. Jpn J Ophthalmol 2001; 45: 209-15. [PMID: 7016805] [http://dx.doi.org/S0021-5155(01)00328-8 [pii]]

[75] Nakayasu K. Stromal changes following removal of epithelium in rat cornea. Jpn J Ophthalmol 1988; 32(2): 113-25. [PMID: 3054215]

[76] Campos M, Raman S, Lee M, McDonnell PJ. Keratocyte loss after different methods of de-epithelialization. Ophthalmology 1994; 101(5): 890-4. [http://dx.doi.org/10.1016/S0161-6420(94)31242-5] [PMID: 8190476]

[77] Wilson SE, He YG, Weng J, et al. Epithelial injury induces keratocyte apoptosis: hypothesized role for the interleukin-1 system in the modulation of corneal tissue organization and wound healing. Exp Eye Res 1996; 62(4): 325-7.

[http://dx.doi.org/10.1006/exer.1996.0038] [PMID: 8795451]

[78] Hay ED. Development of the vertebrate cornea. Int Rev Cytol 1980; 63: 263-322. [http://dx.doi.org/10.1016/S0074-7696(08)61760-X] [PMID: 395131]

[79] Jester JV, Barry PA, Lind GJ, Petroll WM, Garana R, Cavanagh HD. Corneal keratocytes: in situ and in vitro organization of cytoskeletal contractile proteins. Invest Ophthalmol Vis Sci 1994; 35(2): 730-43.

[PMID: 8113024]

[80] Berryhill BL, Kader R, Kane B, Birk DE, Feng J, Hassell JR. Partial restoration of the keratocyte phenotype to bovine keratocytes made fibroblastic by serum. Invest Ophthalmol Vis Sci 2002; 43(11): 3416-21. [PMID: 12407151]

[81] Beales MP, Funderburgh JL, Jester JV, Hassell JR. Proteoglycan synthesis by bovine keratocytes and corneal fibroblasts: maintenance of the keratocyte phenotype in culture. Invest Ophthalmol Vis Sci 1999; 40(8): 1658-63. [PMID: 10393032]

[82] Erie JC, Patel SV, McLaren JW, Nau CB, Hodge DO, Bourne WM. Keratocyte density in keratoconus. A confocal microscopy study (a). Am J Ophthalmol 2002; 134(5): 689-95.

[http://dx.doi.org/10.1016/S0002-9394(02)01698-7] [PMID: 12429244]

[83] Ku JY, Niederer RL, Patel DV, Sherwin T, McGhee CN. Laser scanning in vivo confocal analysis of keratocyte density in keratoconus. Ophthalmology 115, 845-850, doi:S0161-6420(07)00623-9 2008. [http://dx.doi.org/10.1016/j.ophtha.2007.04.067]

[84] Kim WJ, Rabinowitz YS, Meisler DM, Wilson SE. Keratocyte apoptosis associated with keratoconus. Exp Eye Res 1999; 69(5): 475-81. [http://dx.doi.org/10.1006/exer.1999.0719] [PMID: 10548467]

[85] Ha NT, Nakayasu K, Murakami A, Ishidoh K, Kanai A. Microarray analysis identified differentially expressed genes in keratocytes from keratoconus patients. Curr Eye Res 2004; 28: 373-9. [http://dx.doi.org/10.1080/02713680490502201]

(C) 2017 Soiberman et al.

This is an open access article distributed under the terms of the Creative Commons Attribution 4.0 International Public License (CC-BY 4.0), a copy of which is available at: https://creativecommons.org/licenses/by/4.0/legalcode. This license permits unrestricted use, distribution, and reproduction in any medium, provided the original author and source are credited. 